\title{
Cutaneous Melanoma by AJCC v7 Stage
}

National Cancer Institute

\section{Source}

National Cancer Institute. Cutaneous Melanoma by A/CC v7 Stage. NCI Thesaurus. Code C91231.

A term that refers to the staging of cutaneous melanoma, following the rules of the TNM AJCC V7 classification system. 